\title{
PENINGKATAN KOMPETENSI GURU DAN SISWA MELALUI PEMBUATAN WEBSITE SEKOLAH DI PONDOK PESANTREN AL IHSAN PANDEGLANG
}

\author{
Andhika Octa Indarso, Windhiadi Yoga Sembada, Artambo B. Pangaribuan, \\ Universitas Pembangunan Nasional Veteran Jakarta \\ andyocta@upnvj.ac.id, yoga.sembada@upnvj.ac.id, artambo@upnvj.ac.id
}

\begin{abstract}
Website is a media tool that can be used by anyone, including educational institutions as a means of official, fast, and accessible communication from anywhere. This community service activity held at the Al-Ihsan Pandeglang Islamic Boarding School have a purpose to improve the abilities and selfdevelopment of teachers and students in the world of computers, especially website creation. It is hoped that, after receiving the website creation training, both teachers and students can develop and manage the school's website independently. The problems faced by partners at this time are the absence of specific ICT learning, teachers with limited ICT abilities, students who only have the ability to type, and the absence of an official school website. The implementation method used is assisting in making websites from content to management In this mentoring, pre-test and post-test surveys were also carried out to see the level of knowledge and the effects of the assistance provided. The results of the pre-test and post-test provided showed an increase in knowledge for participants by $29.31 \%$ for basic website creation, and an increase of $34.48 \%$ for knowledge related to website content. The conclusion is that this assistance is effective in increasing participants' knowledge of the creation and management of website content.
\end{abstract}

Keywords: Website, Pesantren, Content, Management

\begin{abstract}
Abstrak
Website menjadi sarana media yang dapat dimanfaatkan oleh siapa saja tak terkecuali oleh institusi pendidikan sebagai sarana komunikasi yang resmi, cepat, dan bisa diakses dari mana saja. Kegiatan pengabdian masyarakat yang diselenggarakan di lingkungan Pondok Pesantren Al-Ihsan Pandeglang ini bertujuan untuk meningkatkan kemampuan dan pengembangan diri bagi para guru dan siswa dalam dunia komputer khususnya pembuatan website, diharapkan setelah menerima pelatihan pembuatan website, baik guru maupun siswa dapat mengembangkan serta mengelola secara mandiri website milik sekolah. Adapun permasalahan yang dihadapi Mitra saat ini adalah tidak adanya pembelajaran TIK secara khusus, guru dengan kemampuan TIK terbatas, siswa yang hanya memiliki kemampuan mengetik, serta tidak adanya website sekolah secara resmi.Metode pelaksanaan yang digunakan adalah melakukan pendampingan pembuatan website mulai dari konten sampai pengelolaan, dalam pendampingan tersebut dilaksanakan juga survei pre test dan post test untuk melihat sejauh mana tingkat pengetahuan dan efek dari pendampingan yang diberikan. Hasil dari pre test dan post test yang diberikan terdapat peningkatan pengetahuan bagi peserta sebesar $29.31 \%$ untuk dasar pembuatan website, dan kenaikan 34,48\% untuk pengetahuan terkait konten website. Kesimpulan yang didapatkan adalah pendampingan ini efektif untuk meningkatkan pengetahuan peserta terhadap pembuatan dan pengelolaan konten website.
\end{abstract}

Kata Kunci: Website, Pesantren, Konten, Pengelolaan 


\section{PENDAHULUAN}

Perkembangan dunia teknologi yang kian pesat, menjadi salah satu faktor penting terciptanya sebuah dunia maya yang dikenal sebagai Internet. Di dalam internet terdapat website atau web atau lebih dikenal sebagai world wide web (www) yang merupakan kumpulan dari berbagai halaman web (web page) yang secara luas merupakan bagian dari sebuah alamat domain atau subdomain yang berisikan berbagai macam informasi di dalamnya. Semua pengguna komputer ataupun smartphone dapat mengakses berbagai macam domain atau halaman web yang ada di dunia maya selama terhubung ke internet.

Sebuah website memiliki fungsi yang berbeda-beda, sesuai dengan tujuan yang ingin dicapai oleh pemiliknya, seperti sebagai media promosi, media pemasaran, media informasi, media pendidikan, dan media komunikasi. Di era digital saat ini, penggunaan website sudah menjadi hal yang umum dilakukan untuk melakukan berbagai aktivitas khususnya di dalam institusi pendidikan, seperti promo program sekolah, menjaring bibit unggul di seluruh penjuru Nusantara, informasi resmi sekolah, dan masih banyak lagi lainnya (Hasugian, 2018).

Bila merujuk pada data APJII (Asosiasi Penyelenggara Jasa Internet Indonesia) di tahun 2018, pengguna internet di Indonesia mencapai 171, 17 juta jiwa atau setara $64,8 \%$ dari total penduduk Indonesia, 264,16 juta jiwa. Bila dipecah per provinsi maka pengguna internet di Pulau Jawa mencapai $55,7 \%$, Sumatera 21,6\%, Kalimantan 6,6\%, Bali dan Nusa Tenggara 5,2\%, Sulawesi-Maluku-Papua 10,9\%. Bila melihat data tersebut, maka sangat disayangkan bila sebuah institusi pendidikan tidak memanfaatkan kesempatan ini untuk dikenal lebih luas lagi ataupun mencari generasi emas para pelajar yang ada di seluruh wilayah Indonesia ("Asosiasi Penyelenggara Jasa Internet Indonesia," n.d.).

Pondok Pesantren Al-Ihsan yang diasuh oleh $\mathrm{KH}$. Asmuni $\mathrm{M}$. Noor memiliki ciri khas sebagai Pondok Pesantren Tahfiz Qur'an. Beragam fasilitas dan gedunggedung sekolah yang mampu menampung ratusan santri dan santriwati ini sangat disayangkan tidak memiliki website sebagai media komunikasi dan informasi. Bahkan untuk mendapatkan profil sekolah ini cukup terbatas sehingga tidak dapat mendapatkan informasi yang lebih banyak mengenai Pondok Pesantren ini. Oleh karena itu, pengabdi memberikan solusi untuk menghadirkan website Pondok Pesantren yang dapat dibuat dan diatur oleh para santri dan santriwati yang nantinya website tersebut tidak hanya sebagai sarana komunikasi dan informasi, juga bisa dijadikan sarana media dakwah di era digital 
saat ini. Internet yang tumbuh dan berkembang pesat sejak tahun 2000an hingga sekarang, memberikan banyak kontribusi di semua sektor kehidupan, mulai dari lingkungan tempat tinggal, tempat kerja, dunia pendidikan, dan masih banyak lagi lainnya.

Hadirnya teknologi internet, menghadirkan sebuah terobosan baru yang diberi nama website. Website menjadi sarana media yang dapat dimanfaatkan oleh siapa saja tak terkecuali oleh institusi pendidikan sebagai sarana komunikasi yang resmi, cepat, dan bisa diakses dari mana saja. Bagi institusi pendidikan, website dapat membuka kesempatan agar dapat dikenal lebih luas lagi oleh masyarakat, menampilkan informasi profil institusi, visi dan misi, sekaligus sebagai sarana promosi untuk menjaring bibit-bibit unggul para calon siswa dari berbagai seluruh penjuru wilayah Nusantara.

Pondok Pesantren Al-Ihsan Pandeglang merupakan salah satu penyelenggara pendidikan tingkat Madrasah Tsanawiyah (MTs) setingkat SMP, dan Madrasah Aliyah (MA) setingkat SMA. Meskipun Pondok Pesantren ini menekankan pada pendidikan ilmu agama, namun di dalamnya terdapat satu Lab Komputer yang dapat digunakan untuk pembelajaran komputer oleh siswa MTs, maupun MA.

Kegiatan pengabdian masyarakat yang diselenggarakan di lingkungan Pondok Pesantren AlIhsan Pandeglang ini untuk meningkatkan kemampuan dan pengembangan diri bagi para guru dan siswa dalam dunia komputer khususnya pembuatan website. Diharapkan, setelah menerima pelatihan pembuatan website, baik guru maupun siswa dapat mengembangkan serta mengelola secara mandiri website milik sekolah.

\section{TINJAUAN LITERATUR}

Website terdiri dari dua jenis berdasarkan sifatnya, yakni dinamis dan statis. Dikatakan dinamis apabila informasi di dalamnya selalu mutakhir ataupun pemiliki situsnya dapat berinteraksi secara langsung dengan para pengunjungnya, contoh Facebook, Detik.com, Youtube.com, dan lain-lain. Sedangkan sebuah website dikatakan statis apabila informasi di dalamnya tidak berubah-ubah dan tidak ada interaksi yang terjadi dengan para pengunjung situsnya. Pembuatan sebuah website terdiri dari beberapa elemen pendukung, seperti nama domain, web hosting, bahasa pemrograman, desain, publikasi atau promosi website, pemeliharaan, dan usia domain (Harningtyas, 2014).

Berkembangnya teknologi informasi dan komunikasi (TIK), telah memberikan pengaruh terhadap dunia pendidikan, khususnya dalam proses pembelajara. Dengan berkembangnya penggunaan TIK ada 5 (lima) pergeseran dalam proses pembelajaran, yaitu: (1) Dari pelatihan ke penampilan; (2) dari ruang kelas ke dimana dan 
kapan saja; (3) dari kertas ke online atau saluran; (4) Fasilitas fisik ke fasilitas jaringan kerja; (5) Dari waktu siklus ke waktu nyata. Hubungan antara guru/dosen degan siswa/mahasiswa tidak hanya dilakukan melalui hubungan tatap muka, tetapi juga dilakukan dengan menggunakan mediamedia komunikasi seperti: telepon, internet, e-mail, dan sebagainya (Hidayat, 2010).

Penggunaan web dalam lingkungan pendidikan merupakan suatu keharusan dalam era Industri 4.0 ini. Kebutuhan akan materi yang terkait dengan teknologi informasi menjadi hal yang mutlak dalam pelaksanaan pendidikan. Sayangnya hal ini sering tidak sebanding dengan praktik di lapangan, keterbatasan kualitas tenaga pengajar seringkali membuat web tidak maksimal. Seperti yang dialami oleh SMK Negeri 1 Surabaya yang mungkin hanya terbatas tahu pada sisi teori namun kurang pada praktik sehingga perlu dibantu pada level keterampilan teknis (Kristanto et al., 2019). Tidak hanya pada sisi teknis namun juga pada level pengelolaan web dimana siswa juga harus akrab dengan aplikasi seperti Content Management System (CMS) milik Wordpress. Aplikasi ini menjadi dasar pengenalan alat bantu bagi pembuatan konten untuk pemula (Pratiwi, Santoso, Mardianto, Sediyono, \& Rochman, 2020).

Web saat ini juga menjadi sarana yang vital bagi sekolah untuk proses belajar mengajar, apalagi di era pandemi saat ini yang mengandalkan teknologi jarak jauh untuk proses belajar mengajar. Seperti yang dilakukan di Unversitas Surabaya bahwa pemanfaatan web sebagai alat bantu untuk proses belajar mengajar, bukan hanya sekedar menempelkan materi disitu tapi juga untuk membuat bagaimana interaksi agar lebih hidup (Lawanto, 2000). Seperti contoh yang terjadi di SMP dan SMA Muhammadiyah di Kartasura, dimana mereka memiliki fasilitas lengkap di webnya dalam proses belajar mengajar, namun kemampuannya mengelolanya masih sangat terbatas (Supriyono, Sujalwo, Sapoetra, \& Rahayu, 2015). Oleh karena itu pihak akademisi punya kewajiban untuk turun tangan dan membantu sekolah-sekolah tersebut untuk mengatasi gap teknologi yang ada.

Alasan kenapa pesantren yang dipilih karena manfaat penggunaan web bagi proses belajar mengajar secara mengejutkan terbukti pada pesantren seperti di Darul Ulum Banyuanyar (Sakur et al., 2020) dan juga bermanfaat sebagai sarana komunikasi pesantren dengan masyarakat luar (Anwas, 2015).

\section{METODE PELAKSANAAN}

Kegiatan ini menggunakan metode riset yang memanfaatkan kuesioner yang akan diberikan di awal dan di akhir pertemuan. Dari hasil survei, dapat menentukan tingkat pengetahuan mengenai pembuatan website. Dalam pemberian edukasi dan praktek diperoleh dari narasumber yaitu dari profesional bersertifikasi dan tim pengajar yang profesional. Diharapkan terjadi peningkatan 
kompetensi khusus, meliputi:

1. Langkah-langkah pembuatan website dari awal.

2. Cara membuat konten website yang berkualitas.

3. Cara mengelola website yang baik dan benar.

Tahapan-tahapan yang akan dilakukan untuk pelaksanaan kegiatan ini, adalah sebagai berikut:

\section{Tahap Pertama:}

Sebelum memulai pelaksanaan program abdimas ini dan agar hasilnya lebih maksimal maka perlu dilakukan pre-test terlebih dahulu kepada para guru dan siswa. Melalui pre-test ini, diharapkan dapat melihat sejauh mana pemahaman mereka mengenai dunia website dari awal hingga akhir. Selain itu, materi pembelajaran yang akan diberikan disesuaikan dengan kebutuhan guru dan siswa berdasarkan hasil pre-test.

\section{Tahap Kedua:}

Sebagai seorang pengajar, para guru akan diberikan materi mengenai dunia website, mulai dari awal hingga akhir. Setelah diberikan materi, para guru akan didampingi dan dilatih cara pembuatan website, mulai dari pemberian nama domain, framework yang akan digunakan, cara mengunggah website, hingga website dapat berjalan dengan baik dan benar. Selain itu, akan turut diberikan pelatihan cara membuat konten yang menarik dengan tampilan multimedia agar pengunjung betah melihat website dengan durasi yang lama. Berikutnya, akan dibekali juga dengan materi cara mengelola website dengan baik. Diharapkan kemampuan para guru meningkat dan bisa diterapkan ataupun diberikan pengajaran di dalam ataupun di luar kelas.

\section{Tahap Ketiga:}

Pada tahap ini diberikan pelatihan untuk para siswa yang ada di Pondok Pesantren. Materi mengenai pemrograman website mulai dari perkembangan teknologi HTML, cara pengaturan layout hingga pengaturan di dalam framework yang berbasis Wordpress yang mudah dipelajari. Selain itu, para siswa akan dibekali kemampuan untuk pembuatan multimedia agar tampilan website terlihat lebih menarik. Pembelajaran multimedia menggunakan Adobe Photoshop yang biasa digunakan untuk melakukan editing gambar ataupun foto.

\section{Tahap Empat:}

Pada tahapan ini, baik guru maupun siswa akan dilakukan post-test yang digunakan untuk melihat sejauh mana pemahaman terhadap materi yang sudah diberikan. Diharapkan para guru maupun siswa terjadi peningkatan kemampuan dalam menggunakan komputer khususnya melakukan pembuatan website. Dari hasil post-test ini akan dipilih tim yang akan melakukan pengerjaan pembuatan website resmi milik Pondok Pesantren Al-Ihsan dan didampingi oleh tim pengajar. 


\section{HASIL DAN PEMBAHASAN}

Pengabdian kepada masyarakat yang digelar di Pondok Pesantren AlIhsan Pandeglang ini bertujuan untuk membangun situs Pondok Pesantren yang dibuat dan dikelolah oleh mereka secara mandiri. Hal ini penting untuk dilakukan mengingat mereka memiliki potensi untuk menjadi Pondok Pesantren pilihan utama di wilayah Banten. Pelaksanaan pengabdian kepada masyarakat ini mengalami penundaan tiga bulan akibat adanya pandemi Covid-19 yang membuat wilayah Banten dan sekitarnya menutup akses dari wilayah sekitarnya, sehingga membuat kegiatan menjadi banyak yang tertunda. Pelaksanaan kegiatan pengabdian ini baru dapat dilaksanakan di bulan Agustus.

Ada beberapa tahapan yang dilakukan sebelum melakukan pengabdian masyarakat ini, seperti:

1. Melakukan konsolidasi dengan tim yang terdiri atas dosen dan mahasiswa.

2. Mempersiapkan materi presentasi tentang pembuatan website yang dilengkapi dengan cara membuat konten website yang menarik.

3. Mempersiapkan bahan Pre-Test dan Post-Test.

4. Survei ke lokasi mitra.

Pelaksanaan pengabdian kepada masyarakat dilakukan setelah Banten menerapkan New Normal, yakni pada: Hari/Tanggal : Sabtu / 22 Agustus 2020 Pukul : 10:00 s/d 17:00 Tempat : Pondok Pesantren AlIhsan, Kadomas, Pandeglang, Banten.

Saat pelaksanaan, pengabdi tidak melibatkan peran mahasiswa karena mengutamakan kesehatan dan keselamatan masing-masing mahasiswa. Mahasiswa dilibatkan pada saat sebelum pelaksanaan dimulai, seperti melakukan layout modul pelatihan, membantu menyiapkan presentasi, dan sebagainya.

Kedatangan kami disambut oleh $\mathrm{H}$. Dodi Ahmadi, Lc yang merupakan salah satu pengasuh Yayasan Al-Ihsan dan Kepala Sekolah Pondok Pesantren, Saepulloh, S.Th.I. Selaku perwakilan dari Yayasan, H. Dodi menerima kedatangan kami dengan positif dan merasa senang atas niat kami untuk membantu mereka dalam menyiapkan pembuatan website Pondok Pesantren.

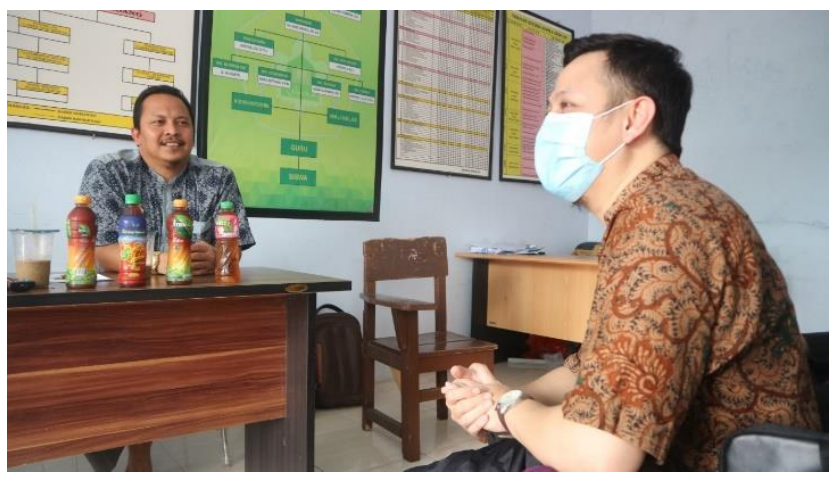

Gambar 1. Perwakilan Yayasan Al-Ihsan, H. Dodi menyambut Kedatangan Tim Dosen 
Sebelum tim dosen melakukan presentasi, siswa dan guru diminta untuk melakukan pengisian pretest yang sudah kami siapkan. Sebagai bentuk minimalisir penularan Covid-19, kami melakukan pengambilan data pretest dan post-test dengan menggunakan Google Form.

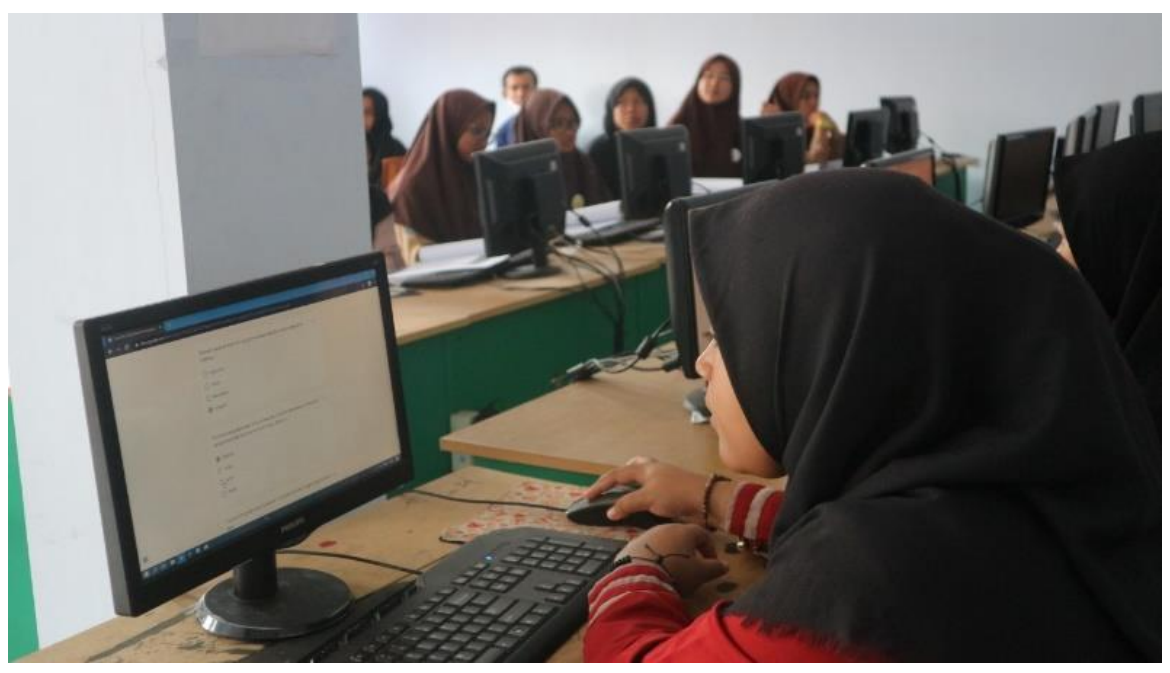

Gambar 2. Suasana Pengisian Kuesioner oleh Siswa Ponpes Al-Ihsan Melalui Google Form

Ada beberapa pertanyaan mendasar yang dipertanyakan ke responden, mulai dari perangkat keras yang digunakan untuk mengakses internet, lokasi mengakses internet, dan sebagainya. Selain itu, kami turut mempertanyakan hal-hal mendasar mengenai pertanyaan dasar Website dan pertanyaan seputar Konten di website. Data-data yang berhasil dihimpun adalah sebagai berikut:

Perangkat keras yang digunakan oleh Anda untuk mengakses internet?

29 responses

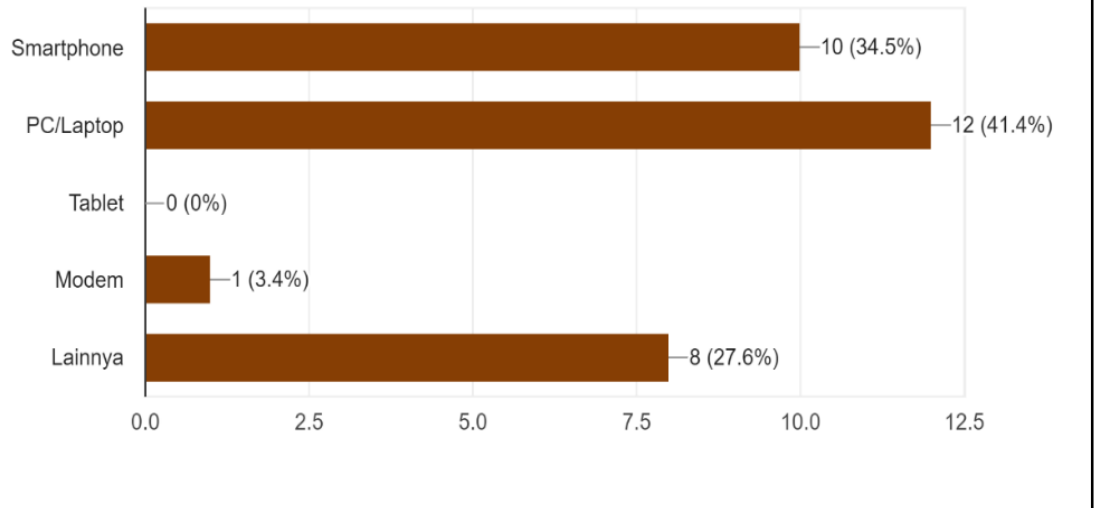

Gambar 3. Hasil Responden Mengenai Perangkat Keras untuk Akses Internet 
Dari data-data di atas bisa dilihat bahwa mayoritas responden masih lebih memilih akses via PC/Laptop. Smartphone sendiri meskipun sudah menjadi bagian dari kehidupan anak muda sehari-hari tidak menjadi pilihan utama. Hal ini bisa dimaklumi karena pihak pesantren tidak mengizinkan para santri untuk membawa gadget ke dalam pesantren, sehingga akses utama para santri hanya pada PC yang tersedia di Pesantren. Hal ini sesuai juga dengan PKM-PKM terdahulu yaitu bagaimana sekolah mendorong santri untuk memanfaatkan fasilitas yang ada dalam mengakses internet secara terkendali (Anwas, 2015)

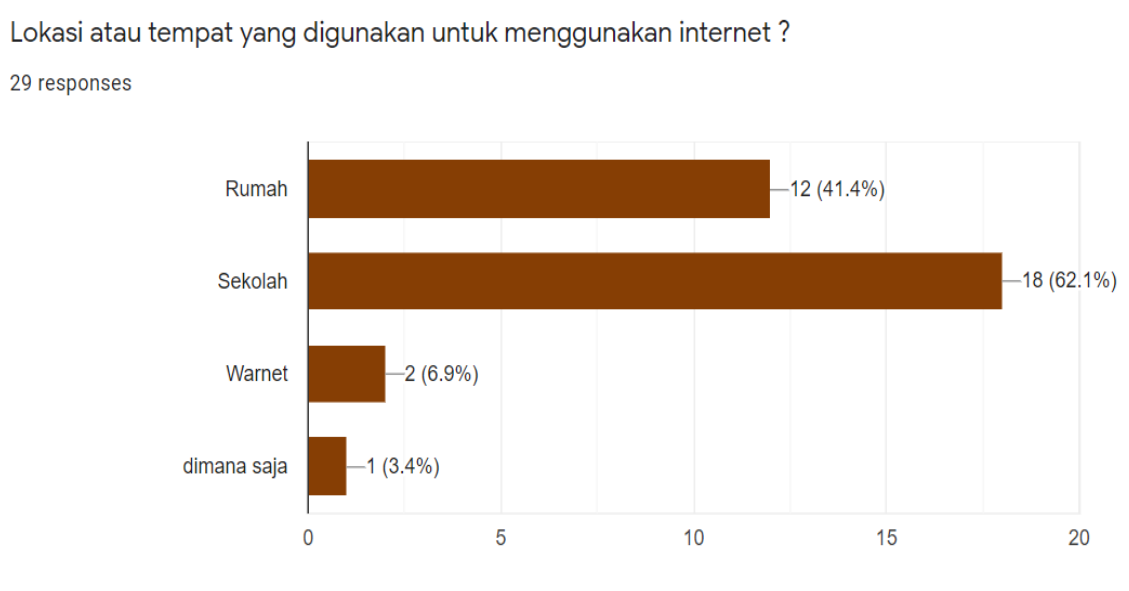

Gambar 4. Hasil Responden Mengenai Lokasi Mengakses Internet

Hasil kuesioner ini di Pesantren ini wajar terjadi karena memperlihatkan bahwa para responden responden tinggal di asrama dan lebih banyak mengakses internet lewat menghabiskan waktu lebih banyak di pesantren ketimbang di rumah. sana.

Tingginya angka pengaksesan internet

Jenis website apa yang paling sering Anda buka

29 responses

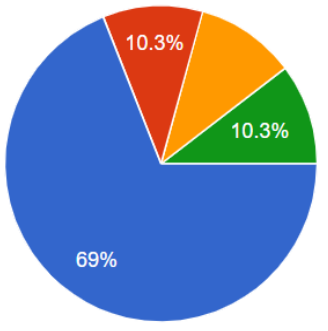

Media Sosial (Twitter, Facebook, dll)

- Situs Berita

Hiburan (game online, entertainment

Pendidikan dan IPTEK

Gambar 5. Hasil Responden Mengenai Jenis Website yang sering dibuka

Sarwahita : Jurnal Pengabdian Kepada Masyarakat Vol. 17 No. 2 Tahun 2020|150 
Melihat hasil diagram diatas tidak mengherankan, karena responden masih rata-rata berusia 14 - 15 tahun, yang memang sedang getol-getolnya bermain media sosial. Selebihnya yang mengakses website untuk keperluan berita dan pendidikan hanya 10 persen. Berdasarkan informasi inilah yang menjadi bahan dari penyuluhan kami, dengan coba mempersuasi peserta untuk lebih banyak memanfaatkan akses-akses informasi yang valid untuk keperluan

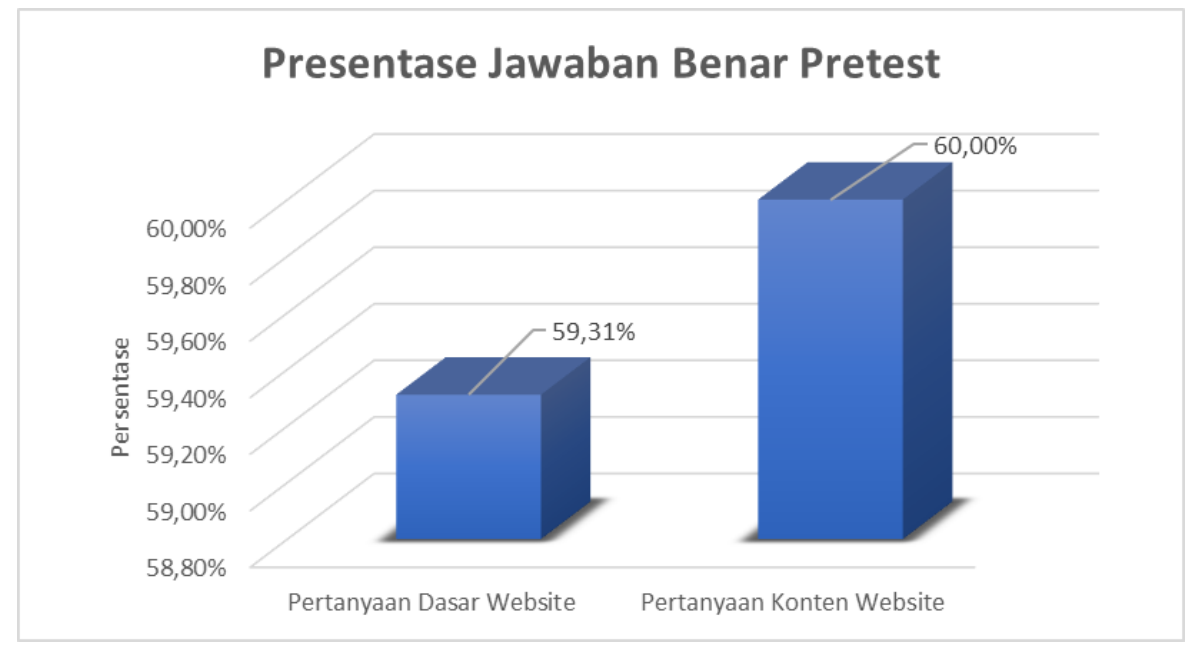

Gambar 6. Hasil Rerata Jawaban Benar Pretest Responden

Setelah kami melakukan pretest, kami pun mulai melakukan presentasi mengenai dasar-dasar website dan konten website yang telah disiapkan atas arahan dan koordinasi oleh Ing. Artambo B. Pangaribuan. Presentasi dipandu oleh Andhika Octa Indarso,
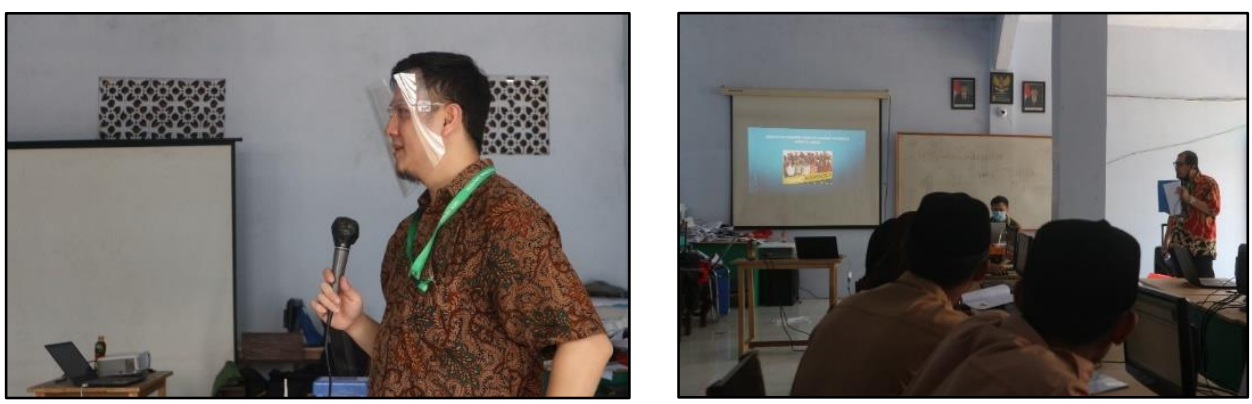

Gambar 7. Suasana Pemberian Materi di depan Santri Ponpes Al-Ihsan Pandeglang

Setelah diberikan materi oleh tim dosen, peserta diminta untuk mengisi kuesioner posttest yang sudah disiapkan. Hasilnya ternyata terdapat kenaikan yang signifikan dari hasil
S.Kom., M.MSI (FIK) yang membawakan seputar dasar website, lalu Whindiadi Yoga Sembada, S.I.Kom., M.Si (FISIP) yang membawakan seputar konten website yang bernilai positif. jawaban keseluruhan soal yang
disiapkan terdiri dari butir-butir
pertanyaan mengenai dasar-dasar
website dan konten website. Pelatihan
ini menimbulkan antusiasme yang 
sangat besar dari kalangan para santri, karena mereka sendiri baru memahami kegunaan maksimal dari internet untuk mencari informasi. Hal ini sama dengan hal yang dilakukan kegiatan pada pesantren Pabelan (Kumoro et al., 2018)

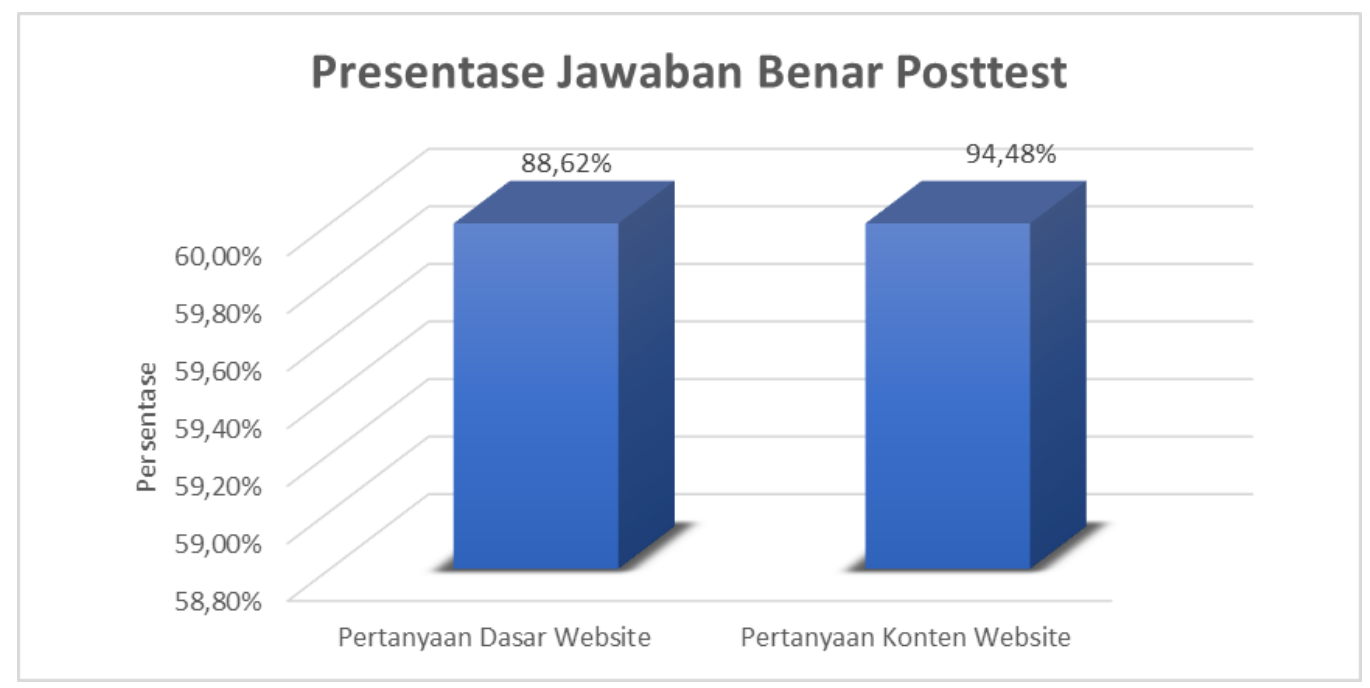

Gambar 8. Hasil Rerata Jawaban Benar Posttest Responden

Hasil jawaban dari posttest menunjukkan bahwa terdapat kenaikan sebesar $29.31 \%$ untuk pertanyaan seputar dasar website, dan terdapat kenaikan $34.48 \%$ untuk pertanyaan mengenai konten website seperti yang ditunjukan pada gambar 9 .

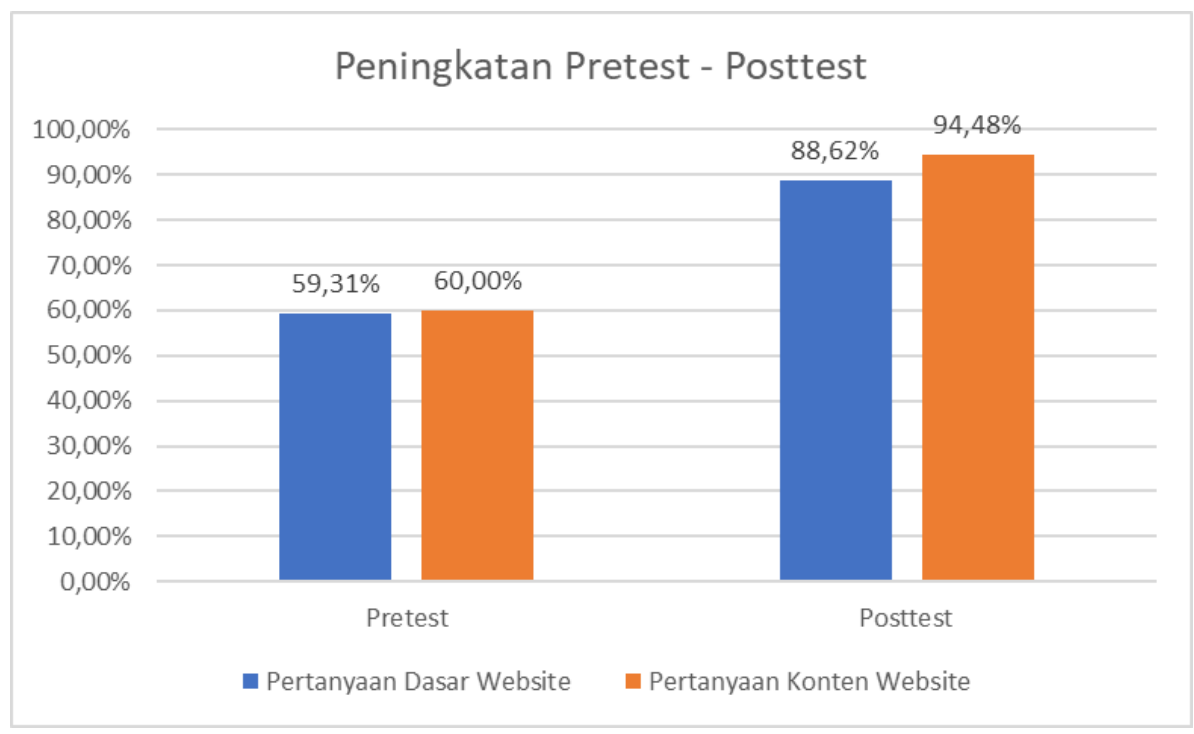

Gambar 9. Terdapat Peningkatan Hasil Posttest dibandingkan Pretest

Peningkatan ini menunjukkan adanya tambahan pemahaman dari peserta setelah mengikuti pelatihan seperti yang juga ditunjukkan pada jurnal-jurnal sebelumnya (Anwas, 2015; Arifin \& Setiawan, 2019; Sakur et al., 2020) 


\section{PENUTUP}

Kesimpulan yang didapatkan dari hasil pengabdian masyarakat bahwa tingkat pengetahuan peserta cukup meningkat dari sebelum diberi pelatihan. Keterbatasan yang ada selama masa pelatihan seperti pandemik covid19 tidak menyurutkan antusiasme para peserta. Saran ke depannya perlu ada pendampingan keberlanjutan untuk memantau sampai sejauh mana website yang dikelola oleh para siswa ini

\section{DAFTAR PUSTAKA}

Anwas, O. M. (2015). Pemanfaatan Teknologi Informasi dan Komunikasi pada Pesantren Rakyat Sumber Pucung Malang. Jurnal Pendidikan Dan Kebudayaan, 21(3), 207. https://doi.org/10.24832/jpnk.v21i 3.187

Arifin, M., \& Setiawan, R. R. (2019). Peningkatan Kapasitas Santri Pondok Pesantren Entrepreneur Al-Mawaddah Kudus Melalui Pelatihan Web. Muria Jurnal Layanan Masyarakat, 1(1), 2227.

Asosiasi Penyelenggara Jasa Internet Indonesia. (n.d.). Retrieved November 21, 2020, from https://apjii.or.id/survei2018

Harningtyas, R. (2014). ANALISIS LAYANAN WEBSITE SEBAGAI MEDIA PROMOSI, MEDIA TRANSAKSI DAN MEDIA INFORMASI DAN PENGARUHNYA TERHADAP BRAND IMAGE PERUSAHAAN PADA HOTEL CIPUTRA DI KOTA SEMARANG. Jurnal STIE Semarang, 11(44), 129-141.
Retrieved from http://fsctold.modares.ac.ir/article_10614_3 0aea192f59914fbe55c62ccc37ee4 40.pdf

Hasugian, P. S. (2018). Perancangan Website Sebagai Media Promosi Dan Informasi. Journal of Informatic Pelita Nusantara, 3(1), 82-86.

Hidayat, R. (2010). ANALISIS TINGKAT PENGGUNAAN INTERNET DIKALANGAN MAHASISWA DAN HUBUNGANNYA DALAM PENINGKATAN NILAI AKADEMIK (Studi Kasus pada Mahasiswa di Kota Medan). Jurnal Mediasi, 2(2), 55-63.

Kristanto, T., Rahmawati, D., Nurdin, A., Putro, F. W., Wicaksono, A. Y., \& Sholik, M. (2019). Pelatihan Keterampilan WEB Design Bagi Siswa SMK Negeri 1 Surabaya. Randang Tana: Jurnal Pengabdian Masyarakat, 2(2), 310. Retrieved from http://unikastpaulus.ac.id/jurnal/in dex.php/jrt/article/view/393

Kumoro, D. T., Bachtiar, A., Hasanah, U., Fanny, R., Ardi, P., \& Informasi, T. (2018). PENERAPAN DAN PELATIHAN TEKNOLOGI INFORMASI SEBAGAI MEDIA INFORMASI DAN PENERIMAAN SISWA BARU DI PONDOK PESANTREN PABELAN. Prosiding PKM-CSR, $1,65-74$.

Lawanto, O. (2000). Pembelajaran Berbasis Web Sebagai Metoda Komplemen Kegiatan Pendidikan Dan Pelatihan*. Unitas, 9(1), 4458.

Pratiwi, D., Santoso, G. B., Mardianto, I., Sediyono, A., \& Rochman, A. 
(2020). Pengelolaan Konten Web Menggunakan Wordpress, Canva dan Photoshop untuk Guru-Guru Wilayah Jakarta Web Content Management Using Wordpress , Canva and Photoshop for Teachers of the Jakarta Region. Jurnal Ilmiah Pengabdian Pada Masyarakat, 2(1), 11-15.

Sakur, A., Informatika, T., Teknik, F., Madura, U., Raya, J., \& No, P. (2020). Sistem informasi pondok pesantren darul ulum banyuanyar berbasis web dan android 1,2, 6(2), 23-29.

Supriyono, H., Sujalwo, S., Sapoetra, A., \& Rahayu, E. T. (2015). Pelatihan Pengembangan Media Pembelajaran Berbasis Web Bagi Guru Smp Dan Sma Muhammadiyah Kartasura. Warta LPM, 18(2), 98-109. https://doi.org/10.23917/warta.v1 $8 \mathrm{i} 2.1949$ 